\title{
Adsorption of microcystins by carbon nanotubes
}

\author{
Hai Yan ${ }^{\text {a,b,*, }}$ Aijun Gong ${ }^{\text {a }}$, Hongsheng He ${ }^{\text {a }}$, Jie Zhou ${ }^{\text {a }}$, Yuxia Wei ${ }^{\text {a }}$, Le Lv ${ }^{\text {a }}$ \\ ${ }^{a}$ Department of Biological Science and Technology, University of Science and Technology Beijing, No. 30 Xueyuan Road, \\ Haidian District, Beijing 100083, China \\ b State Key Laboratory of Environmental Aquatic Chemistry, Research Center for Eco-environmental Sciences, \\ Chinese Academy of Sciences, P.O. Box 2871, Beijing 100085, China
}

Received 12 January 2005; received in revised form 17 March 2005; accepted 21 March 2005

Available online 12 May 2005

\begin{abstract}
The production of cyanobacterial toxins microcystins (MCs) by cyanobacterial bloom which may promote the growth of tumor in human liver is a growing environmental problem worldwide. In this paper, the adsorption of MC-RR and LR, which were extracted from cyanobacterial cells in Dianchi Lake in China, by carbon nanotubes (CNTs), wood-based activated carbon (ACs) and clays were investigated. Compared with ACs and clay materials of sepiolite, kaolinite and talc tested, CNTs were found to have a strong ability in the adsorption of MCs. At the concen-

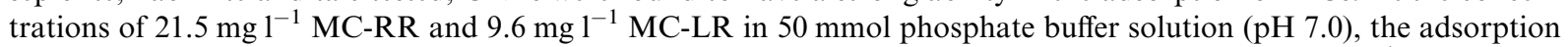
amounts of MCs by CNTs with the range of outside diameter from 2 to $10 \mathrm{~nm}$ were 14.8 and $5.9 \mathrm{mg} \mathrm{g}^{-1}$, which were about four times higher than those by other adsorbents tested. It was shown that with the decrease of CNTs outside diameters from 60 to $2 \mathrm{~nm}$, the adsorption amount of MCs was apparently increased, however the size of CNTs particles formed in solution declined. This result implies that the size of CNTs tube pore that is fit for the molecular dimension of MCs plays a dominant role. Furthermore the specific surface area of CNTs was also found to be a factor in the adsorption of MCs. The results suggested that the selection of suitable size of CNTs as a kind of adsorbent is very important in the efficient eliminating MCs from drinking water in future.
\end{abstract}

(c) 2005 Elsevier Ltd. All rights reserved.

Keywords: Microcystin-RR; Microcystin-LR; Carbon nanotubes; Activated carbon; Clays; Adsorption

\section{Introduction}

With the increasing in the discharge of wastewater containing nitrogen and phosphorus to rivers and lakes, harmful cyanobacteria blooms (HCB) in natural waters have become a growing environmental problem world-

\footnotetext{
* Corresponding author. Address: Department of Biological Science and Technology, University of Science and Technology Beijing, No. 30 Xueyuan Road, Haidian District, Beijing 100083, China. Tel.: +861062333177.

E-mail address: haiyan@sas.ustb.edu.cn (H. Yan).
}

wide (Dawson, 1998; Kaebernick and Neilan, 2001; Haider et al., 2003). Recently, HCB has appeared all year round in the Dianchi Lake in China, and the contents of microcystin-RR (MC-RR) and -LR (MC-LR) in dry cyanobacterial cells collected from the surface water of Dianchi Lake were determined as 1.3 and $0.8 \mathrm{mg} \mathrm{g}^{-1}$ (Yan et al., 2002, 2004a).

Microcystins (MCs) are a family of cyanobacterial toxins produced by Microcystis, Oscillatoria, Nostoc and Anabaena, which are monocyclic heptapeptides composed of seven amino acids containing an unusual amino acid (2S, 3S, 8S, 9S)-3-amino-9-methoxy-2,6, 
8-trimethyl-10-phenyldeca-4,6-dienoic acid (Adda) that is essential for the expression of biological activity (Dawson, 1998). Among more than 60 types of MCs identified, MC-RR and LR were the dominant types of MCs worldwide (Haider et al., 2003), which have been found from fresh water bodies to oceans and shown tumor promoting activity through the inhibition of protein phosphatases (Fujiki and Suganuma, 1999). Recently, a provisional safety guideline of $1.0 \mu \mathrm{g} \mathrm{l}^{-1}$ MC-LR in drinking water was recommended by WHO (Falconer, 1999).

Generally, MCs are very stable in the water body and resistant to be removed from drinking water by traditional water treatment technology (Falconer, 1999; Haider et al., 2003), so it is very important to investigate the new efficient method for the removal of MCs using different technology containing adsorbents. Pendleton et al. (2001) found that the wood-based activated carbons (ACs) that contain both micropores and mesopores adsorbed more MC-LR than the coconut-based ACs that contain micropores only, however surface and solution chemistry played minor roles in the adsorption process. Donati et al. (1994) also investigated the adsorption by several different powdered ACs and suggested that the removal of MC-LR was directly proportional to the mesopore volume (diameters between 2 and $50 \mathrm{~nm}$ ) of adsorbents. Mohamed et al. (1999) demonstrated that the powdered ACs were more efficient than granular ACs in removing MCs, and MCs from extracts of Microcystis aeruginosa were adsorbed significantly better than those from Oscillatoria tenuis. Morris et al. (2000) reported that MC-LR could be scavenged by fine-grained particles contained high concentration of the clay minerals of kaolinite and montmorillonite. Miller et al. (2001) also demonstrated that the soil with high clay and organic carbon content had the higher adsorption coefficient of MCs.

Carbon nanotubes (CNTs) have unique properties owing to their particular structure and are the probable constituents of future materials in many purposes. Although CNTs as a new valuable material for the storage of hydrogen gas, methane and carbon monoxide were widely investigated (Darkrim et al., 2002; Gu et al., 2002; Tanaka et al., 2002), the adsorption of MCs by CNTs was not reported previously.

\section{Materials and methods}

\subsection{Adsorbents}

CNTs with different outside diameters from 2 to $60 \mathrm{~nm}$ produced by Tsinghua-Nafine Nano-Powder Commercialization Engineering Center and Shenzhen Nanotech Port Co., Ltd. were investigated. The wood-based activated carbons (ACs) bought from commercial company, and the clays of sepiolite $(90 \%$ purity), kaolinite $(80 \%$ purity) and talc ( $70 \%$ purity) bought from China National Non-Metallic Minerals Industry Import and Export Corporation were also used as the absorbents, which were all sieved through a net with the pore diameter of $83 \mu \mathrm{m}$ before the experiment.

\subsection{Extraction and purification of MCs}

MC-RR and LR producing cyanobacteria floating in the surface water of Dianchi Lake in China were taken on July, 2001 and air dried. Briefly, the dried cyanobacterial cells were smashed with a grinder and cyanobacterial powder passed through net with the pore diameter of $121 \mu \mathrm{m}$ was used to extract MC-RR and LR using $40 \%$ (v/v) methanol solution. The extracted solution was firstly passed through a cartridge (Waters, OASIS $\left.^{\mathrm{TM}} \mathrm{HLB}\right)$ and then $70 \%(\mathrm{v} / \mathrm{v})$ methanol was used to elute MC-RR and LR (Yan et al., 2004a). The elution was dried at $70{ }^{\circ} \mathrm{C}$ by an evaporator (Buchi Rotavapor R-200), and solid MC-RR and LR remained was dissolved with distilled water, and then filtered by a $0.45 \mu \mathrm{m}$ membrane, and finally used in the adsorption experiment. The purity of MC-RR and LR were about $7.3 \%$ and $3.5 \%$ (MC carbon/TOC).

\subsection{Experimental conditions}

In the adsorption experiment, $10 \mathrm{mg}$ of CNTs, ACs or clay was added to $10 \mathrm{ml}$ of $50 \mathrm{mmol}$ phosphate buffer ( $\mathrm{pH}$ 7.0) containing semi-purified MC-RR and LR in a $50 \mathrm{ml}$ flask. The experiments were conducted with shake rate of $150 \mathrm{rpm}$ at $30^{\circ} \mathrm{C}$. The samples taken at different intervals for each condition were centrifuged at $12787 \mathrm{~g}$ for $10 \mathrm{~min}$ and supernatant was used to determine the concentrations of MC-RR and LR on HPLC. Data presented here were the average value determined three times with standard deviation. Furthermore the diameter distribution and zeta potential of CNTs particles formed in buffer solution ( $\mathrm{pH}$ 7.0) were also measured with a Mastersizer 2000 Analyzer and a Zetasizer 2000 (Malvern, UK).

\subsection{Determination of $M C s$}

Standard MCs of MC-LR and MC-RR bought from Sigma (95\% purity) and the sample solutions containing extracted and purified MCs were accurately determined on a HPLC (Shimadzu-LC10A) with a Diode Array Detector at the wavelength of $239 \mathrm{~nm}$ using a column of Waters (Bondapak C18 column $(300 \times 3.9 \mathrm{~mm})$. The mobile phase was $40 \%$ (v/v) acetonitrile-water solution containing $0.03 \%(\mathrm{v} / \mathrm{v})$ of trifluoroacetic acid. The flow-rate was $1.0 \mathrm{ml} \mathrm{min}^{-1}$ and the injection amount was $20 \mu 1$. 


\section{Results}

\subsection{Extraction and purification of $M C s$}

Fig. 1 was the HPLC profiles of standard and purified MC-RR and LR. The peak retention time of $10 \mathrm{mg}^{-1}$ standard MC-RR and LR were 4.75 and $7.30 \mathrm{~min}$ (Fig. 1a), which were same to those of purified MC-RR and LR (Fig. 1b). Furthermore the scanning profiles of purified MC-RR and LR in the ultraviolet range from 200 to $300 \mathrm{~nm}$ showed that the maximum absorbance of two peaks were all at $239 \mathrm{~nm}$ or so (Fig. 2 ), which further verified that the two extracted and purified compounds were MC-RR and LR.

\subsection{Adsorption of MCs by CNTs, ACs and clays}

Compared with those of no absorbent added after $1 \mathrm{~d}$, the concentrations of MC-RR and LR in solution were much decreased from 21.5 and $9.6 \mathrm{mg}^{-1}$ to 6.7 and $3.7 \mathrm{mg}^{-1}$ in the presence of $1.0 \mathrm{~g}^{-1}$ CNTs with outside diameters from 2 to $10 \mathrm{~nm}$, respectively
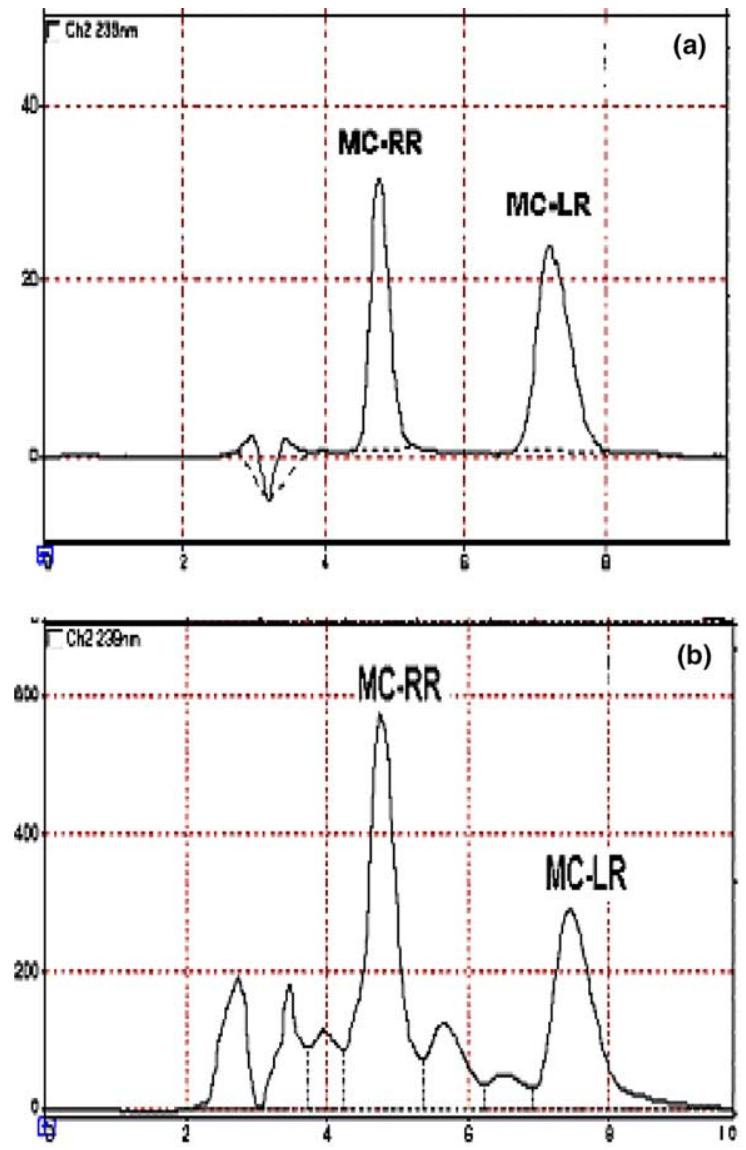

Fig. 1. HPLC profiles for the standard (a) and purified (b) MCRR and MC-LR, respectively.
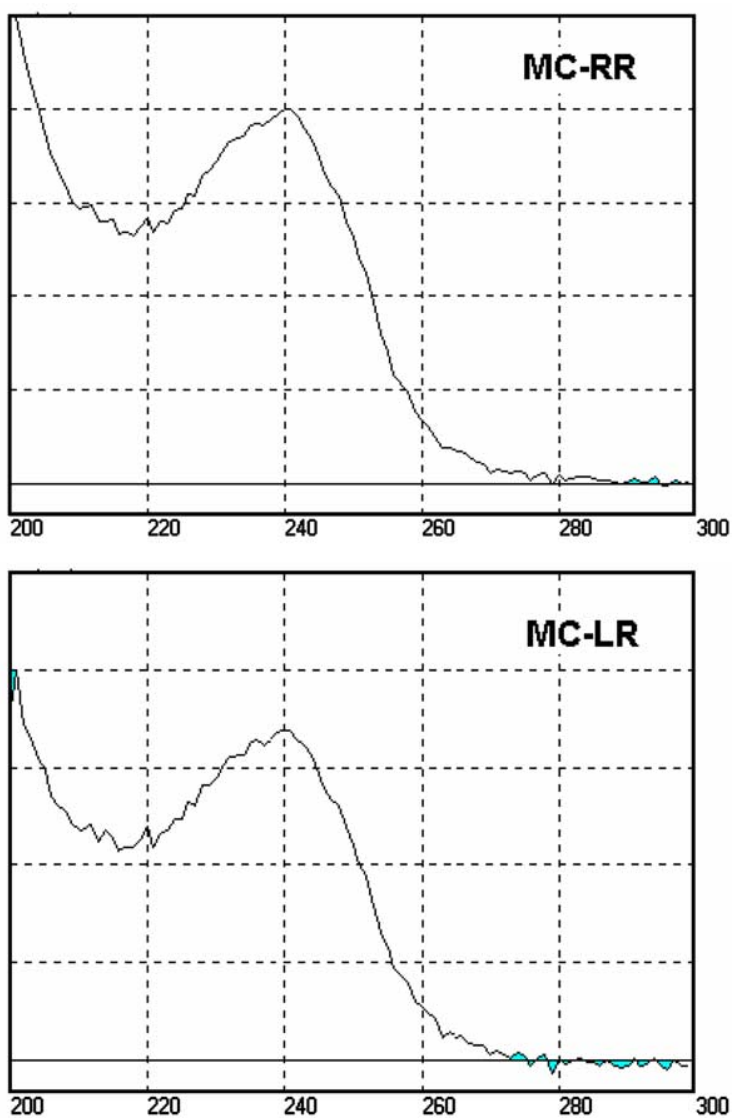

Fig. 2. Absorbance profiles of purified MC-RR and MC-LR in the ultraviolet wavelength from 200 to $300 \mathrm{~nm}$, respectively.

(Fig. 3a). However the contents of MC-RR and LR in solution were slightly reduced when ACs or different clays of $1.0 \mathrm{~g} \mathrm{l}^{-1}$ were added (Fig. 3a). The calculated adsorption amounts of MC-RR and LR by CNTs were 14.8 and $5.9 \mathrm{mg} \mathrm{g}^{-1}$, which were about four times higher than those by ACs and clays tested, respectively (Fig. 3b).

\subsection{Adsorption of MCs by CNTs with different sizes}

Fig. 4 was the adsorption dynamics of MCs by $1.0 \mathrm{~g} \mathrm{l}^{-1} \mathrm{CNTs}$ with different outside diameters. At initial MC-RR of $13.2 \mathrm{mg} \mathrm{l}^{-1}$ and MC-LR of $8.7 \mathrm{mg} \mathrm{l}^{-1}$, the concentrations of both MC-RR (Fig. 4a) and LR (Fig. 4b) were all sharply decreased before $8 \mathrm{~h}$ and then almost kept constant, which indicated that the period of $8 \mathrm{~h}$ was needed to reach the adsorption equilibriums of MCs. With the decrease of CNT outside diameters from 60 to $2 \mathrm{~nm}$, the concentrations of MC-RR and LR in solution also apparently declined at $24 \mathrm{~h}$, which showed that CNTs with smaller outside diameter could absorb more MCs (Fig. 4). At $24 \mathrm{~h}$ the calculated adsorption amounts of MC-RR and LR by CNTs with the range 

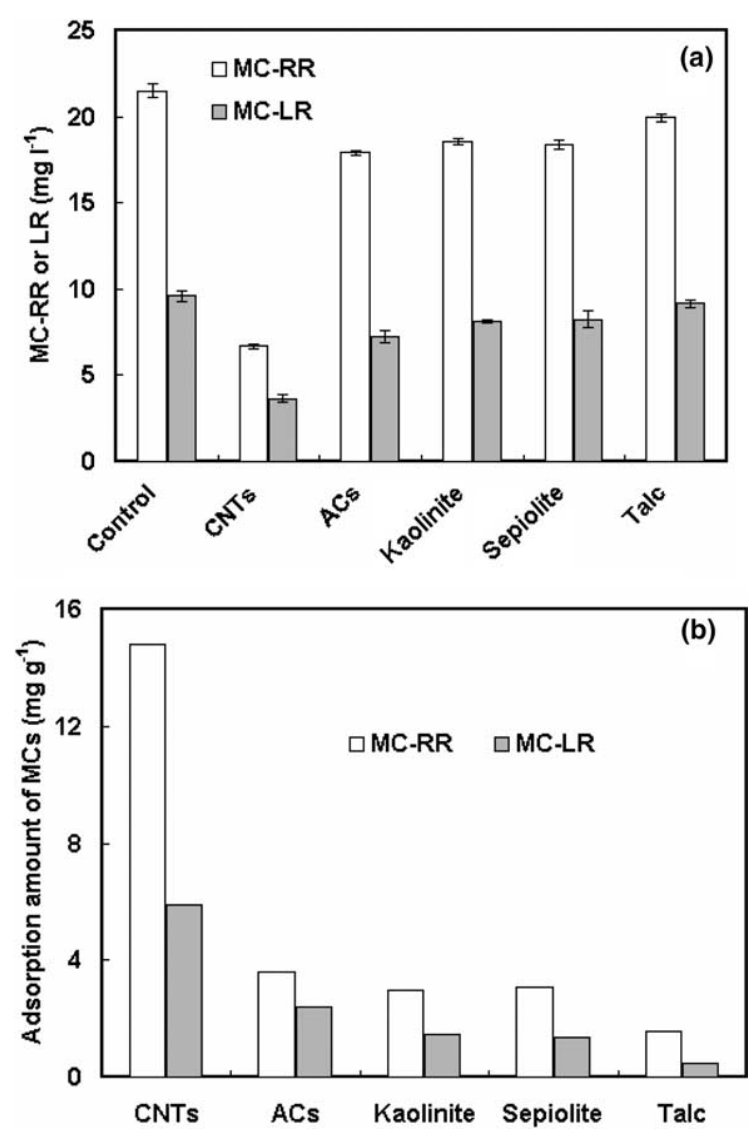

Fig. 3. Adsorption of MC-RR and LR by CNTs, ACs and the different clays of sepiolite, kaolin and talc in $50 \mathrm{mmol}$ phosphate buffer ( $\mathrm{pH}$ 7.0) for $1 \mathrm{~d}$. (a) Change of MC-RR and LR concentrations in solution and (b) adsorption amounts of MC-RR and LR.

of outside diameter from 2 to $10 \mathrm{~nm}$ were 8.1 and $4.5 \mathrm{mg} \mathrm{g}^{-1}$, which were much higher than those of 2.8 and $1.1 \mathrm{mg} \mathrm{g}^{-1}$ by CNTs with the range of outside diameters from 30 to $60 \mathrm{~nm}$, respectively.

\subsection{Diameters and charge of CNTs particles formed in solution}

Fig. 5 was the diameter distribution of CNTs particles formed in $50 \mathrm{mmol}$ phosphate buffer solution $(\mathrm{pH}$ 7.0), which was measured with a Laser Particle Analyzer. It was shown that the average diameter of CNTs particles with the outside diameter range from 2 to $10 \mathrm{~nm}$ was $14.8 \mu \mathrm{m}$ (Fig. 5a). With the increase of CNT outside diameter ranges from $10-30 \mathrm{~nm}$ to 30 $60 \mathrm{~nm}$, the average diameters were also increased to 52.4 and $202.4 \mu \mathrm{m}$ (Fig. 5b and c), respectively. The results showed that the size of CNTs particles formed was positive proportion to the outside diameter of CNTs.
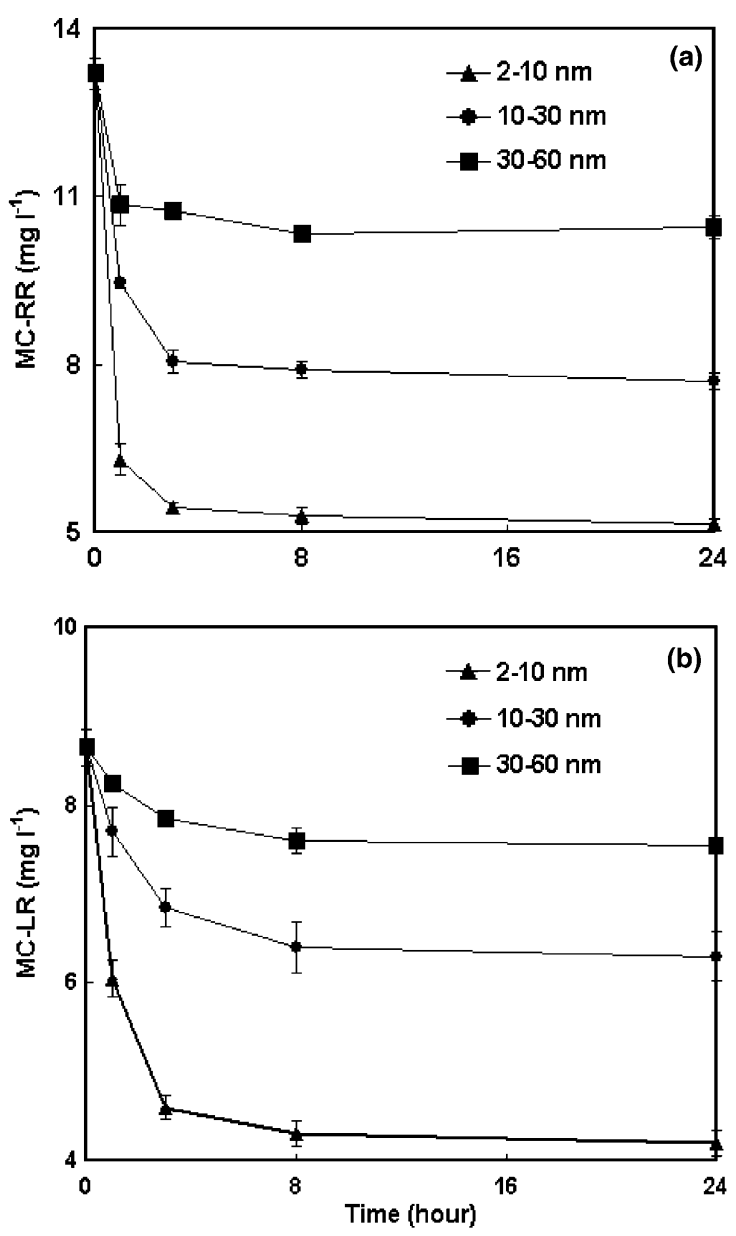

Fig. 4. Adsorption of MC-RR (a) and LR (b) by carbon nanotubes with different outside diameters in $50 \mathrm{mmol}$ phosphate buffer ( $\mathrm{pH} 7.0)$.

The charge potential of CNTs particles formed in phosphate buffer solution ( $\mathrm{pH}$ 7.0) was also determined with a Zetasizer 2000, which all displayed the net negative charges from -22 to $-27 \mathrm{mV}$ (Fig. 6).

\section{Discussion}

\subsection{Production and extraction of MCs}

All toxins related to MCs had very similar UV spectra with the maximum of absorption at the wavelengths from 238 to $242 \mathrm{~nm}$ (Lawton et al., 1994; Moollan et al., 1996), in present studies the maximum absorbance of MC-RR and LR were all at about $239 \mathrm{~nm}$ that was selected to determine the concentrations of MCs quantificationally (Figs. 1 and 2). Generally the possibility of HCB to produce cyanobacterial toxins was $50 \%$ or so (Duy et al., 2000), but both MC-RR and LR could be 

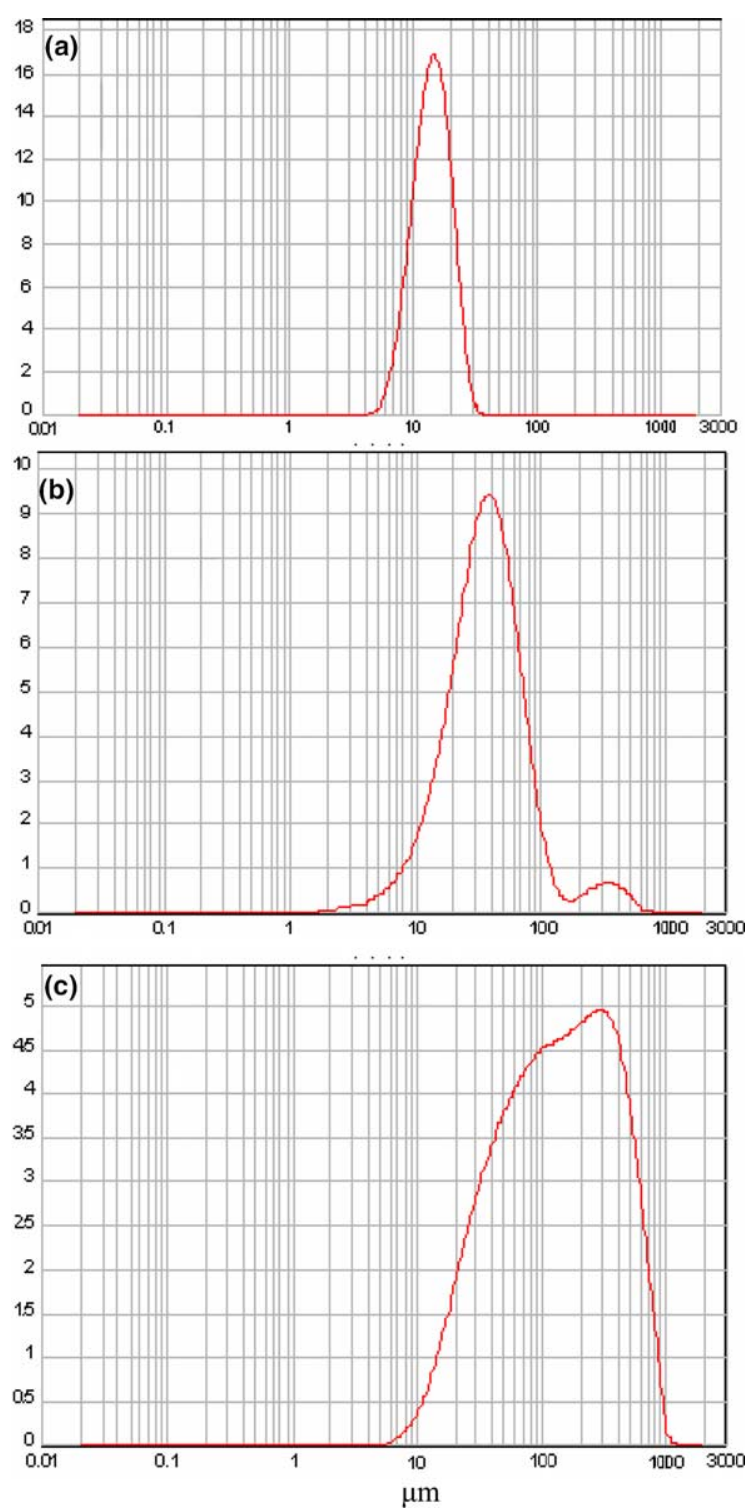

Fig. 5. Diameter distribution of formed particles of CNTs with different outside diameters from 2 to $10 \mathrm{~nm}$ (a), 10 to $30 \mathrm{~nm}$ (b) and 30 to $60 \mathrm{~nm}$ (c) in $50 \mathrm{mmol}$ phosphate buffer ( $\mathrm{pH} \mathrm{7.0)}$.

produced by HCB in Dianchi Lake in China (Figs. 1 and 2 ), which might cause a serious problem when the water of this lake was ready to use as the source of drinking water.

Many different methods were introduced and the different ratios of methanol were found to be the most effective solutions for the extraction of MCs (Lawton et al., 1994; Lawton and Edwards, 2001). Here 40\% (v/ v) methanol between 0 and $80 \%(\mathrm{v} / \mathrm{v})$ was found to be the optimal solution to extract MCs from the powder of cyanobacterial cells collected from Dianchi Lake
Outside diameter range of CNTs $(\mathrm{nm})$

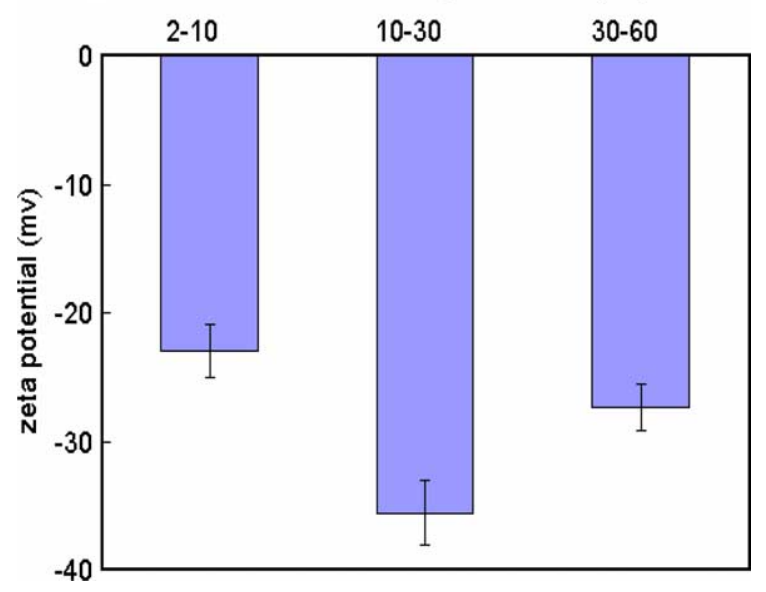

Fig. 6. Charge potentials of formed particles of CNTs with different outside diameters in $50 \mathrm{mmol}$ phosphate buffer $(\mathrm{pH}$ 7.0).

(Yan et al., 2004a). After the extraction solution of $40 \%(\mathrm{v} / \mathrm{v})$ methanol containing MCs was passed through a cartridge (Waters, OASIS ${ }^{\mathrm{TM}}$ HLB Cartridge), MCs were purified by the elution with $70 \%(\mathrm{v} / \mathrm{v})$ methanol. Due to the expensive price of pure MCs, the extracted and semi-purified MC-RR and LR from cyanobacterial cells using this method were successfully prepared and used in this experiment (Fig. 1).

\subsection{Adsorption of MCs by CNTs, ACs and clays}

The fine particles containing high content of kaolinite and montmorillonite were found to have the abilities in absorbing MC-LR (Morris et al., 2000), however our results indicated that the adsorption amounts of MCs by clays of sepiolite, kaolinite and talc were all much lower than those by CNTs (Figs. 3 and 4). Although the adsorption ability of MCs by wood-based powdered ACs was slightly higher than those of clays tested (Fig. 3 ), which was also lower than those of some reports (Donati et al., 1994; Mohamed et al., 1999; Pendleton et al., 2001). In order to keep the same condition, the adsorbents were all directly used without treatment prior to our experiment, which might cause the differences in the absorbed amounts of MCs. On the other hand some natural organic matters contained in reaction solution reduced the adsorption capacity of MCs and Lambert et al. (1996) also found that the very little of MC-LR at low concentration was removed by ACs in the presence of a biofilm or natural organic compounds, which might be responsible for lower absorbed amounts of MCs by ACs and clays in our experiment (Fig. 3).

Lahti and Hiisvirta (1989) indicated that the concentrations of MCs hardly changed when small doses of 
powdered ACs were added, but Donati et al. (1994) reported that the removal of MCs was a direct proportionality of ACs mesopore volume. Furthermore the decrease of $\mathrm{pH}$ was found to cause the increase in the adsorption of MCs by ACs (Pendleton et al., 2001), which is in accordance with the properties that the solubility of MC-LR in water was decrease with the increase of pH (De Maagd et al., 1999). In order to keep the stable $\mathrm{pH}$, the phosphate buffer ( $\mathrm{pH}$ 7.0) solution was adopted as reaction solution in the experiment. Here we demonstrated that CNTs with outside diameter range from 2 to $10 \mathrm{~nm}$ could absorb much more MC$\mathrm{RR}$ and LR, and the adsorption amount of MCs was about four times higher than those by ACs and clays tested (Fig. 3).

\subsection{Adsorption of MCs by CNTs with different sizes}

Adsorption equilibrium of MCs by CNTs with different outside diameters quickly reached at $8 \mathrm{~h}$ or so, because the concentrations of MCs were almost kept constant after $8 \mathrm{~h}$ (Fig. 4). With the decrease of outside diameter of CNTs, the adsorption amounts of MC-RR and LR were apparently increased (Fig. 4), which showed that the size of CNTs played a dominant role in the adsorption of MCs. Because the surface structures of CNTs with different outside diameters were similar, the decrease of specific surface area of bigger CNTs particles formed in solution with the increase of CNTs size might be another factor for the decline of MCs adsorption (Fig. 5). Although particle charge is a very important factor in the difference of adsorption, the charge potentials of CNTs particles with different sizes in solution were all displaying the net negative charges (Fig. 6), which indicated that pore size and specific surface area rather than charge potentials of CNTs may mainly be responsible for the difference in the adsorption amounts of MCs.

When MC-LR was dissolved in water, the solvated volume is about $2.63 \mathrm{~nm}^{3}$ and the longest molecular length is approximately $1.9 \mathrm{~nm}$ (Lanaras et al., 1991). When the adsorption of MCs was studied, the pore size in absorbent must be considered in order to fit for the molecular dimensions of MCs. The size of mesopore from 2 to $50 \mathrm{~nm}$ on the surface of wood-based ACs was responsible for the higher adsorption amount of MCs than those by the coconut-based ACs containing micropore below $2 \mathrm{~nm}$ only (Pendleton et al., 2001). According to this viewpoint, the outside diameters from 2 to $10 \mathrm{~nm}$ of CNTs might be just suitable for this requirement of longest length of $1.9 \mathrm{~nm}$ in the dimension of molecular MC-LR, so the adsorption amounts of both MC-RR and LR by CNTs with outside diameters from 2 to $10 \mathrm{~nm}$ were much high than those by CNTs with bigger outside diameters. On the other hand, the size of pores just fitting for the dimension of MCs may cause the more combination sites between the MCs molecules and adsorption groups on the intra-surface of CNTs, however much large tube pores may cause less groups connected with MCs, which may easily be desorbed from CNTs. Therefore less MCs were desorbed and more MCs were absorbed by CNTs with small size of diameters than those by CNTs with the large outside diameters.

Owing to their nanometric diameters, CNTs have a very large specific surface areas, which may be a very promising material used in the adsorption. Peigney et al. (2001) found that the specific surface areas of CNTs declined with the increase of their diameter, which may be another factor in the decrease of adsorption amounts of MCs by CNTs with large outside diameter (Fig. 4). Yan et al. (2004b) observed that the biodegradation of MCs by an isolated bacterial strain of Ralstonia solanacearum could be promoted by CNTs, because $R$. solanacearum and CNTs could be coalescent each other in water solution and the effective biodegradation of MCs could be conducted on the surface of CNTs.

In the phosphate buffer solution of $\mathrm{pH}$ 7.0, CNTs did not exist as a single tube, which might connect and aggregate together to form the bigger particles with the diameter of micron level (Fig. 5). With the increase of CNTs outside diameters, the size of formed particles also increased (Fig. 5), which might decline the specific surface area and be responsible for the decrease of adsorption amounts of MCs. Because the charge potentials of CNTs particles with different ranges of outside diameters were all displaying the negative charges (Fig. 6), which was not an important factor in the adsorption of MCs.

\section{Conclusions}

The production of MC-RR and LR by the cyanobacterial cells in Dianchi Lake in China was verified. The semi-purified MC-RR and LR with the method of $40 \%$ $(\mathrm{v} / \mathrm{v})$ methanol extraction and $70 \%(\mathrm{v} / \mathrm{v})$ methanol elution were obtained, which was successfully prepared and used in the adsorption experiments. Compared with powdered wood-based ACs and the clays of kaolinite, speolite and talc, CNTs with the range of outside diameters from 2 to $10 \mathrm{~nm}$ were found to have a strong ability in the adsorption of MC-RR and LR. The adsorption amounts of MCs were about four times higher than those by ACs and clays tested. It was shown that the adsorption amounts of MC-RR and LR were increased with decrease of outside diameter of CNTs, which was indicated that the size of CNTs tube pore that is fit for the molecular dimension of MCs was playing a dominant role. Furthermore the specific surface area of CNTs might also be another factor in the adsorption of MCs. The selection of CNTs pore that is just suitable for the 
dimension of molecular MCs can absorb much more amounts of MCs, which is a very promising new material for the removal of MCs from drinking water.

\section{Acknowledgments}

The research was jointly funded by the National Nature Sciences Foundation of China (30270277, 20377047), the National Key Program for Natural Water Quality Improvement (2002AA60101) and State Key Laboratory of Microbial Resources, Institute of Microbiology, Chinese Academy of Sciences (031029). Comments of three anonymous reviewers were greatly appreciated.

\section{References}

Darkrim, F.L., Malbrunot, P., Tartaglia, G.P., 2002. Review of hydrogen storage by adsorption in carbon nanotubes. Int. J. Hydrogen Energy 27, 193-202.

Dawson, R.M., 1998. The toxicology of microcystins. Toxicon 36, 953-962.

De Maagd, P.G., Hendriks, A.J., Seinen, W., Sijm, D.T.H.M., 1999. pH-Dependent hydrophobicity of the cyanobacteria toxin microcystin LR. Water Res. 33, 677-680.

Donati, C., Drikas, M., Hayes, R., Newcombe, G., 1994. Microcystin-LR adsorption by powdered activated carbon. Water Res. 28, 1735-1742.

Duy, T.N., Lam, P.K.S., Shaw, G.R., 2000. Toxicology and risk assessment of fresh water cyanobacterial (blue-green Algae) toxins in water. Rev. Environ. Contam. Toxicol. 163, 113-186.

Falconer, I.R., 1999. An overview of problems caused by toxic blue-green algae (cyanobacteria) in drinking and recreational water. Environ. Toxicol. 14, 5-12.

Fujiki, H., Suganuma, M., 1999. Unique captures of the okadaic acid activity class of tumor promoters. J. Can. Res. Clin. Oncol. 6, 177-184.

Gu, C., Gao, G.H., Yu, Y.X., Nitta, T., 2002. Simulation for separation of hydrogen and carbon monoxide by adsorption on single-walled carbon nanotubes. Fluid Phase Equilibria 194-197, 297-307.

Haider, S., Naithani, V., Viswanathan, P.N., Kakkar, P., 2003. Cyanobacterial toxins: a growing environmental concern. Chemosphere 52, 1-21.

Kaebernick, M., Neilan, B.A., 2001. Ecological and molecular investigations of cyanotoxin production. FEMS Microbiol. Eco. 35, 1-9.
Lahti, K., Hiisvirta, L., 1989. Removal of cyanobacterial toxins in water treatment processes: review of studies conducted in Finland. Water Supply 7, 149-154.

Lambert, T.W., Holmes, C.F.B., Hrudey, S.E., 1996. Adsorption of microcystin-LR by activated carbon and removal in full scale water treatment. Water Res. 30, 14111422.

Lanaras, T., Cook, C.M., Eriksoon, J.E., Meriluoto, J.A.O., Hotokka, M., 1991. Computer modeling of the 3-dimensional structures of the cyanobacterial hepatotoxins microcystin-LR and nodularin. Toxicon 29, 901-907.

Lawton, L.A., Edwards, C., Codd, G.A., 1994. Extraction and high-performance liquid chromatographic method for the determination of microcystins in raw and treated waters. Analyst 119, 1525-1530.

Lawton, L.A., Edwards, C., 2001. Purification of microcystins. J. Chromatogr. A 912, 191-209.

Miller, M.J., Critchley, M.M., Hutson, J., Fallowfield, H.J., 2001. The adsorption of cyanobacterial hepatotoxins from water onto soil during batch experiments. Water Res. 35, $1461-1468$.

Mohamed, Z.A., Carmichael, W.W., An, J., El-Sharouny, H.M., 1999. Activated carbon removal efficiency of microcystins in an aqueous cell extract of Microcystis aeruginosa and Oscillatoria tenuis strains isolated from Egyptian freshwaters. Environ. Toxicol. 14, 197-201.

Moollan, R.W., Rae, B., Verbeek, A., 1996. Some comments on the determination of microcystin toxins in water by highperformance liquid chromatography. Analyst 121, 233-238.

Morris, R.J., Williams, D.E., Luu, H.A., Holmes, C.F.B., Andersen, R.J., Calvert, S.E., 2000. The adsorption of microcystin-LR by natural clay particles. Toxicon $38,303-$ 308.

Peigney, A., Laurent, C., Flahaut, E., Bacsa, R.R., Rousset, A., 2001. Specific surface area of carbon nanotubes and bundles of carbon nanotubes. Carbon 39, 507-514.

Pendleton, P., Schumann, R., Wong, S.H., 2001. MicrocystinLR adsorption by activated carbon. J. Colloid Interface Sci. 240, 1-8.

Tanaka, H., El-Merraoui, M., Steele, W.A., Kaneko, K., 2002. Methane adsorption on single-walled carbon nanotube: a density functional theory model. Chem. Phys. Lett. 352, 334-341.

Yan, H., Pan, G., Zhang, M., 2002. Advances in the study of microcystin toxin (in Chinese). Acta Ecol. Sinica 22, 19681975.

Yan, H., Pan, G., Zhang, M., Chen, H., Zou, H., 2004a. Study on the extraction and purification of microcystins (in Chinese). Acta Scientiae Circumstantiae 24, 355-359.

Yan, H., Pan, G., Hua, Z., Li, X., Chen, H., 2004b. Effective removal of microcystins using carbon nanotubes embedded with bacteria. Chin. Sci. Bull. 49, 1694-1698. 